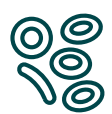

Hematology

-

ดீด

จำ

Oncology

\section{0}

Impact Factor: $\mathbf{3 . 0 6 8}$

CiteScore: $\mathbf{3 . 7}$

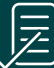

Acceptance rate 14\%

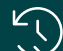

Time to final decision 4 weeks

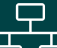

号它

MEDLINE

\title{
Acta Haematologica
}

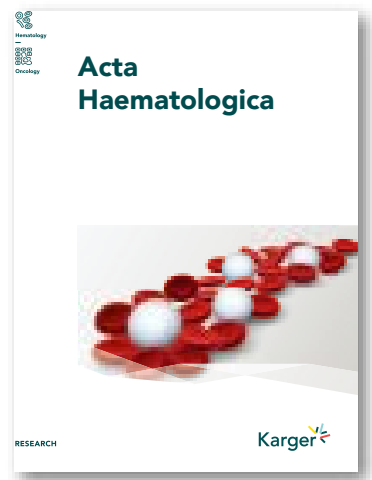

Editor-in-Chief

Pia Raanani (Petah Tikva)

A single source for international hematology research and clinical practice since 1948

Acta Haematologica is a well-established and internationally recognized clinically oriented journal featuring balanced, wide-ranging coverage of current hematology research. A wealth of information on such problems as anemia, leukemia, lymphoma, multiple myeloma, hereditary disorders, blood coagulation, growth factors, hematopoiesis, and differentiation is contained in first-rate basic and clinical research papers - some of which are accompanied by editorial comments by eminent experts. These are supplemented by short state-of-the-art communications, reviews, and correspondence as well as occasional special issues devoted to "hot topics" in hematology. Cutting-edge clinical information, along with translational research relevant to clinical daily life, will keep the practicing hematologist well informed of the new developments in the field.

editorialoffice_aha@ karger.com karger.com/aha 